\title{
CORRESPONDENCE
}

\section{Nuclear Defence}

SIR,--I supported wholeheartedly your editorial "France should not test" (Nature, 243, 50; 1973), but I think that perhaps you were a little unfair in your remark that the French Government would be well advised to admit that its force de frappe is no more than an illusion.

I would, of course, agree that for its advertised purpose as a contribution to the defence of Europe against possible Soviet aggression, its short range and small size make it utterly insignificant if the United States is involved, and, of course, like our nuclear force, more likely to induce preventive attack than to act as a defence if the Russians could be sure that the Americans would not be involved.

I am surprised, however, that you have taken its advertised object at its face value, rather than as the window dressing which it seems to me to be. It is surely easy to believe that the real concern of the French general staff is still, as it has always been, with Ger. many rather than with Russia. This is not even any reflexion on the general well-meaningness of the present West German Government. Governments have changed in this respect in the past, and anyway, general staffs concern themselves with what is possible rather than with what governmental intentions are likely to be. Without nuclear weapons France could offer little resistance to a revanchist Germany and might well doubt the willingness of the United States to destroy such a Germany on behalf of France, and in doing so, destroy their main bulwark in Europe against the USSR.

Ludicrously inadequate as it would be in face of a Russian attack, the force de frappe is in both range and power entirely adequate as a deterrent to a Germany which does not possess such nuclear weapons. One could well blame the French general staff for taking the same narrow and limited view of their country's interests as is taken by all other national general staffs, but I think that it is unfair to blame them for suffering from illusions.

Yours faithfully,

\section{J. H. FREMLIN}

Department of Physics,

Chancellor's Court,

The University of Birmingham,

PO Box 363, Birmingham B15 2TT

\section{Reaching for the Stars}

SIR,-I feel obliged to respond to the two articles "Eye on the Future" and "The Search for Signals from Extraterrestrial Civilizations" (Nature, 241, 363 and $379 ; 1973$ ).

The first of these, an excellent brief review of the Project Cyclops report*, ends by questioning the cost and value of the search for extraterrestrial intelligence: "The scale of expenditure suggested for Cyclops, however, runs at four times the total annual expenditure of the British Science Research Council. Perhaps the question is whether it is more efficient or more satisfying to spend $\$ 600$ million a year asking the stars for, say, a cure for cancer or to spend the same sum on cancer research on Earth." These peculiar comparisons ignore the difference in the potential support base and imply that a cure for cancer would be a major, if not the only, benefit of interstellar contact. Ideally Cyclops would be an international effort; but even excluding this possibility, the $\$ 600$ million/year (during the construction phase only) is only 8 per cent of the 1966 US space budget and 20 per cent of that for 1973 .

Conceivably a cancer cure could be discovered out of interstellar contact (assuming our biochemistry is not too different from theirs), but is only one of a host of potential benefits, many of which may be far more important. Any civilization we contact will be at least as advanced as we and probably much more so. In all probability they will have faced and solved many of the problems that beset the world today such as pollution, depletion of natural resources, population control and the assurance of continued genetic evolution in a compassionate society, to name only a few.

Present theories of galactic evolution and of the origin and evolution of life support the belief that intelligent civilizations have existed in our Galaxy for a few billion years. Interstellar communication may therefore also have existed for aeons, and our first contact could put us in touch, not with another isolated civilization, but with this galactic community. We would then have access to a galactic heritage of knowledge that might include, in addition to a five billion year pictorial record

* Copies available from John Billingham, NASA/Ames Research Center Code LT, Moffett Field, California 94305. of the universe, the Galaxy, and its life forms, some insight into the common cause of intelligent life and its future role. Interstellar contact may well mean childhood's end for the human race. With what other outcome can this be compared?

In the second article James C. G. Walker analyses the consequences of using a type of search strategy that was known to be inadequate before the Cyclops study began. Walker rejects omnidirectional beacons on the grounds that "the power requirement of an isotropic call signal detectable at 100 light years is approximately equal to the world's present total power consumption". He then assumes beamed beacons that illuminate any particular receiver for a short fraction of the time and, not surprisingly, arrives at very pessimistic figures for probable search time. The Cyclops study assumes that the total cost of achieving contact should be minimized by balancing the costs of transmitting and receiving. This leads to receiving antennas several $\mathrm{km}$ in diameter, which can be realized as filled phased arrays. Omnidirectional beacons are then quite feasible and with these the search times are greatly reduced as indicated in Table 1.

Tabie 1 Search Times for Galaxies, using
Walker and Cyclops Strategies

+ Needed to get complete sky coverage otherwise $8 \mathrm{~h}$.

¥ Should be reduced, galactic disk is only about 1,500 light yr thick in solar neighbourhood.

A Cyclops receiving system with an effective clear antenna aperture of $5 \mathrm{~km}$ would detect in 1,000 $\mathrm{s}$ a coherent signal having an incident flux of 5 photons $\mathrm{s}^{-1}$ mile ${ }^{-2} \S$. It would detect a 16 megawatt omnidirectional beacon at 100 light years or a 1,600 megawatt one at 1,000 light years range. Even this latter beacon radiates less than one fourthousandth of the world's present power

§ Since these are $1.5 \mathrm{GHz}$ photons an optical system of equal power sensitivity would have to be able to detect one photon $\mathrm{s}^{-1} /$ hundred thousand square miles. 